\title{
Quality in HIV/AIDS Care Specialty-Related or Experience-Related?
}

$\mathbf{I}_{\mathrm{t} \text { tas }}$ $\mathrm{n}$ this issue, Markson et al. describe the characteristics of New York state clinics caring for Medicaidenrolled outpatients with a new AIDS diagnosis between 1987-92.1 Their work is interesting because these descriptions can be used to measure the process of care provided by various types of clinics. Results suggest that HIV/AIDS-dedicated and infectious disease clinics provide better care than community-based primary care clinics, which in turn provide better care than hospital-based general medicine clinics. While they did not measure clinical outcomes or the costs of care, Markson and colleagues do reference a literature that supports the connection between improved outcomes and the process of care, including for example, access to care and the availability of comprehensive services. Given these results, one might reasonably reconsider the proposition that HIV/ AIDS care is best provided by generalists. ${ }^{2}$

Other studies support such a reconsideration. Markson et al. previously reported that generalists were slow to adopt new HIV therapies. ${ }^{3}$ Primary care practitioners were found to lag 3 years behind AIDS specialists when the proportion of patients receiving antiretroviral therapy within 6 months of an AIDS diagnosis was used as a measure of likelihood to adopt new HIV/AIDS therapies. Gifford et al. reported comparable delays for outpatients of universitybased general medicine practitioners. ${ }^{4}$ They also noted that these patients frequently did not receive the preventive services recommended by the Centers for Disease Control and National Institute of Allergy and Infectious Disease. Curtis et al. asked primary care practitioners to examine a standardized outpatient who simulated being HIV seropositive. ${ }^{5}$ Only $50 \%$ of these practitioners recommended prophylactic isoniazid for a positive tuberculin skin test or recommended appropriate Pneumocystis carinii pneumonia prophylaxis. Only $35 \%$ of them recommended hepatitis screening, $32 \%$ syphilis screening, and $23 \%$ pneumococcal vaccination. Internal medicine residents have shown a comparable lack of knowledge in many of the same areas, as well as poor knowledge about antiretroviral therapy. ${ }^{6}$

These findings should concern generalists. Those who question whether generalists are providing quality care to HIV seropositve outpatients can cite substantial literature to support their claims. Similar questions about generalists' care have been asked in other medical fields, including cardiology and pulmonary medicine. ${ }^{7-12}$ The study and discussion of these questions, however, usually miss the point. Experience rather than board certification may be the critical component necessary to providing quality care. The study of experience and its influence on HIV/AIDS care has begun, and the methods used might serve investigators in other medical fields.

Kitahata et al., for example, studied a group of generalist physicians at a staff-model health maintenance organization. ${ }^{13}$ They reported a 2 -fold increase in the median survival of outpatients with an AIDS-defining illness when the provider was experienced in AIDS care, as opposed to inexperienced. This finding suggests that experience, not specialist training, leads to better care-perhaps because experience provides an impetus for clinicians to upgrade their knowledge of new medications and evolving treatments. Other studies also confirm the relation between a practitioner's experience with HIV/AIDS care and providing better care or having more HIV-related knowledge. ${ }^{5,6,14}$

If experience is the operative link to providing quality care, we should be worried by recent shifts in HIV/AIDS care. In 1996, the Commonwealth of Pennsylvania (representing a trend that is not unique to Pennsylvania) sent a waiver application to the Health Care Financing Administration requesting that all HIV-seropositive Medicaid enrollees in the Philadelphia area receive medical care from managed care institutions. While there are numerous problems with this application, one is directly relevant here: of the four managed care institutions that have proposed contracts so far, none has been able to identify physicians in their networks who are experienced in treating people with HIV/AIDS (N. Feyler, JD, AIDS Law Project of Pennsylvania, January 1997).

These managed care organizations' inability to identify HIV/AIDS-experienced clinicians probably has numerous explanations (other than reducing cost burdens), not the least of which is how one characterizes experience. Measuring a clinician's experience with HIV/AIDS is not easy. Kitahata et al., for example, used a complex algorithm that considered the total number of AIDS patients cared for by a clinician, plus his or her experience with AIDS patients during residency training. ${ }^{13}$ Having cared for more than $5 \mathrm{HIV} /$ AIDS patients and having trained in a residency program in an area with a high incidence of HIV/AIDS were the primary determinants of experience. Other investigators have also included the experience obtained during medical school, or they have simply estimated the total number of HIV seropositve pa- 
tients ever cared for by a clinician. ${ }^{5,6,14}$ Similar methods are being implemented in the real world of practice. Pennsylvania's Department of Public Welfare recently approved an algorithm which defined providers as HIV-experienced if they had a lifetime caseload of 50 HIV/AIDS patients and a current caseload of 10 or more HIV/AIDS patients. ${ }^{15}$ None of these measures of experience has been validated, however, and perhaps as a result, there is limited agreement about how to measure experience.

Until we reach a consensus about how to measure experience with HIV/AIDS care, discussing the relative benefits of generalist versus specialist care is not productive, for two reasons. Generalists, when they are experienced in HIV/AIDS care, appear to provide care equal in quality to that of specialists. Also, generalists are becoming the de facto primary providers for most HIV-seropositve patients (increasingly through state directives). A more productive approach would be to improve knowledge. Primary care practitioners consistently have asked for more knowledge about HIV/AIDS care, and improving information access would meet this demand and might increase quality of care. ${ }^{15-17}$ I have several suggestions that are intended to improve information access.

Several standards of HIV/AIDS care have been published. ${ }^{18-20}$ Some describe standards for HIV/AIDS care, in general, and some specifically address standards for prophylaxis and treatment of opportunistic infections, or antiretroviral management. A regularly updated standard of care is also available from Critical Path AIDS Project, at the internet address http://www.critpath.org/soc10.htm (or by phone at 215-545-2212). The National Aids Treatment Information Project provides a free, automated, fax service about many aspects of HIV/AIDS care (800-399AIDS). Alternatively, reference specialists can answer questions or provide referrals for treatment questions through the federally-supported HIV/AIDS Treatment Information Service (800-HIV-0440). Many HIV/AIDS-related continuing medical education programs can be accessed via conference calls or through AIDS Education and Training Centers. ${ }^{21}$ Finally, numerous HIV/AIDS-related internet sites are available, some of which provide up-todate information regarding treatment, methods for posing questions to newsgroups, and search engines or links that can help find other useful sites. Those interested might try the following sites: http://www.aidsnyc. org/ network, http://www.projinf.org, and http://pslgroup. com/AIDS.HTM. Let me clarify, however, that information access will not always suffice. When highly complex management decisions are required, access to an experienced clinician (not necessarily a specialist) will continue to be necessary.

Additional sources of information are available to clinic directors who want to provide a practice environment conducive to high-quality care. Many clinic characteristics described by Markson et al. are recognized as state-of-the-art features of HIV/AIDS primary care, such as: extended hours; continuity of care; and the presence of nutritionists, case managers, social workers, and an HIV/AIDS director. ${ }^{1}$ Until more is known about the relations between state-of-the-art features of care and clinical or cost outcomes, clinic directors should consider including these services. A limited literature might help directors make these decisions. ${ }^{22,23}$ Clinics should also have quality standards for their HIV/AIDS care, plus a method to assess whether these quality standards are met. ${ }^{24}$ Practitioners should have access to the sources of information described in the preceding paragraph. Finally, I believe that one clinician (an HIV/AIDS director, for example) should be designated to update sources of information regularly and to supply continuing medical education to colleagues.

As the medical care of HIV seropositve individuals becomes more complex, generalists and specialists alike are being inundated with information regarding new medications, new treatment regimens, and new standards of care. The ability to appraise this information critically and incorporate it into practice depends on many things, the least of which appears to be whether one is a generalist or a specialist. Clinical experience appears to be much more important. Until better measures exist for determining how much experience is necessary, the best interim strategy is to give clinicians access to emerging information and to create practice settings that are conducive to highquality HIV/AIDS care.-WILliam C. Holmes, MD, Center for Clinical Epidemiology and Biostatistics, University of Pennsylvania, Philadelphia.

\section{REFERENCES}

1. Markson LE, Turner BJ, Cocroft J, Houchens R, Fanning TR. Clinic services for persons with AIDS: experience in a high prevalence state. J Gen Intern Med. 1997;12:141-149.

2. Cooke M, Libman H, Smith MD. Controversies in the management of HIV-related illnesses. J Gen Intern Med. 1991;6(Suppl 1):S46S55.

3. Markson LE, Cosler LE, Turner BJ. Implications of generalists' slow adoption of zidovudine in clinical practice. Arch Intern Med. 1994: 154: 1497-504.

4. Gifford AJ, McPhee SJ, Fordham D. Preventive care among HIVpositive patients in a general medicine practice. Am J Prev Med. 1994;10:5-9.

5. Curtis JR, Paauw DS, Wenrich MD, Carline JD, Ramsey PG. Physicians' ability to provide initial primary care to an HIV-infected patient. Arch Intern Med. 1995;155:1613-8.

6. Schultz P, Bindman AB, Cooke M. Proficiency of internal medicine residents in outpatient care of patients with HIV infection. J Gen Intern Med. 1994;9:459-61.

7. Ayanian JZ, Hauptman PJ, Guadagnoli E, Antman EM, Pashos $\mathrm{CL}, \mathrm{McNeil} \mathrm{BJ}$. Knowledge and practices of generalist and specialist physicians regarding drug therapy for acute myocardial infarction. N Engl J Med. 1994;331:1136-42.

8. Barry HC. Knowledge of drugs for myocardial infarction: generalists versus specialists. N Engl J Med. 1995;332:472.

9. Justice AC. Knowledge of drugs for myocardial infarction: generalists versus specialists. N Engl J Med. 1995;332:472-3.

10. Hnatiuk O, Moores L, Loughney T, Torrington K. Evaluation of internists' spirometric interpretations. J Gen Intern Med. 1996;11: 204-8. 
11. Greenfield S. Dividing up the turf: generalists versus specialists. J Gen Intern Med. 1996;11:245-6.

12. Nielson EG. When does a generalist need specialist? J Gen Intern Med. 1996;11:247-8.

13. Kitahata MM, Koepsell TD, Deyo RA, Maxwell CL, Dodge WT, Wagner EH. Physicians' experience with the acquired immunodeficiency syndrome as a factor in patients' survival. N Engl J Med. 1996;334:701-6.

14. Curtis JR, Paauw DS, Wenrich MD, Carline JD, Ramsey PG. Ability of primary care physicians to diagnose and manage Pneumocystis carinii pneumonia. J Gen Med Intern Med. 1995;10:395-9.

15. Samuels ME, Shi L, Stoskopf CH, Richter DL, Baker SL, Sy FS. Incentives for physicians to treat HIV-seropositve patients: results of a statewide survey. South Med J. 1993;86:403-8.

16. Gleeson CJ, Havron A, Wadland WC. Family physician management of HIV and AIDS: a Vermont Study. J Fam Pract. 1994;39: 50-4.

17. Lewis CE. AIDS-related experiences of primary care physicians in rural California, 1995. West J Med. 1996;164:415-8.

18. Center for Disease Control. USHPS/IDSA guidelines for the pre- vention of opportunistic infections in persons infected with human immunodeficiency virus: a summary. MMWR. 1995;44(RR-8):1-34.

19. Carpenter CCJ, Fischl MA, Hammer SM, et al. Antiretroviral therapy for HIV infection in 1996: recommendations of an international panel. JAMA. 1996;276:146-54.

20. Bartlett JG. Medical Management of HIV Infection. Glenview, IL: Physicians and Scientists Publications; 1996.

21. Macher A, Goosby E, Barker L, et al. Educating primary care providers about HIV disease: multidisciplinary interactive mechanisms. Public Health Rep. 1994;109:305-10.

22. Smith MD. Primary care and HIV disease. J Gen Intern Med. 1991;6(Suppl 1):S56-S62.

23. Samet JH, Libman H, LaBelle C, et al. A model clinic for the initial evaluation and establishment of primary care for persons infected with human immunodeficiency virus. Arch Intern Med. 1995;155: 1629-33.

24. Bozzette SA, Asch S. Developing quality review criteria from standards of care for HIV disease: a framework. J Acquir Immune Defic Syndr Hum Retrovirol. 1995;8(Suppl 1):S45-S52.

\section{JGIM's E-mail Address}

For Letters to the Editor or for information about submitting manuscripts to JGIM: Walklett@mail.med.upenn.edu 